\title{
Accident-related neurogenic fecal incontinence: a retrospective study
}

Jie Liu

Anhui Medical University

Ruiling Wei

Anhui Medical University

Dewei Wu

Anhui Medical University

Hulin Chen

Anhui Medical University

Juan Dong

Anhui Provincial Hospital

Chaolan Lv

Anhui Provincial Hospital

Xiuli Zhu

Anhui Provincial Hospital

Yue Yu ( $\nabla$ yuyuemd@163.com )

\section{Research article}

Keywords: Neurogenic fecal incontinence; Accident-related; Anorectal motility; The quality of life;

Psychological health

Posted Date: October 15th, 2019

DOl: https://doi.org/10.21203/rs.2.16065/v1

License: () (1) This work is licensed under a Creative Commons Attribution 4.0 International License.

Read Full License 


\section{Abstract}

Abstract Background To evaluate the anorectal motility characteristics, the quality of life and psychological health of accident-related neurogenic fecal incontinence(ArNFI) patients. Methods A retrospective study was conducted on 26 patients with ArNFI visiting the gastrointestinal motility center of affiliated provincial hospital of Anhui medical university were collected as research objects from January 2016 to August 2019. The anorectal motility characteristics of these patients were recorded and analysed by high resolution manometry (HRM), 10 healthy subjects for the same period were recruited as the control group. The psychological characteristics of these patients and healthy subjects were compared by HAMA and HAMD scores,and their quality of life was investigated by SF36. Results Anal sphincter resting pressure in the ArNFI group was more lowwer than that of the control group $(21.18 \pm 4.68 \mathrm{vs} 34.83 \pm 14.13$, $\mathrm{P}<0.05)$. Anorectal compliance in the ArNFI group was more lowwer than that of the control $(1.41 \pm$ $0.32 v s 4.03 \pm 1.06, P<0.05)$. Maximal squeeze pressure were in the ArNFI group was also lowwer than that of the control(53.66 \pm 14.59 vs $143.95 \pm 19.82, \mathrm{P}<0.05)$. HAMA , HAMD scores of the ArNFI group in the ArNFI group were all higher than that of the control ( $21.29 \pm 2.06$ vs $7.63 \pm 1.41 ; 22.00 \pm 3.70$ vs $8.75 \pm 1.91$, respectively.all $\mathrm{P}<0.01$ ). There were significant differences between $\mathrm{SF36}$ scores of ArNFI group and the control group in the 8 dimensions of $P F, R P, G H, V T, S F, R E$ and $M H .(P<0.01)$. Conclusion In patients with ArNFI,there were significantly reduced anorectal motility characteristics, increased HAMA.HAMD scores,and their life quality was obviously declined.

\section{Background}

Fecal incontinence $(\mathrm{FI})$ refers to outflowing of intestinal contents beyond patients control repeatedly,resulting from overflow, reduced storage capacity, disruption of external anal sphincter or puborectalis muscle, weakness of internal anal sphincterand decreased perception of rectal sensation. FI can be divided into passive fecal incontinence (the patient's feces leaked out unconsciously), urgent fecal incontinence (the patient's feces leaked out consciously but uncontrollably) and fecal leakage (the patient's feces leaked out after a normal defecation).[1] The prevalence of FI in the general population is $1.0 \% \sim 7.4 \%$.[2] According to the cause of $\mathrm{FI}$, it can be divided into neurogenic fecal incontinence and myogenic fecal incontinence. Neurogenic fecal incontinence $(\mathrm{NFI})$ is relatively common in clinical and it is the important type of fecal incontinence. It seriously reduces the quality of life and affects the mental healthy of patients because the patients with NFI can not control the time, frequency and degree of defecation.[3]

Accident-related neurogenic fecal incontinence(ArNFI) refers to the injury of the brain, brainstem and nervous system above the sacral ganglion caused by accidents, leading to the disorder of defecation emptying and anal self-control, which is one of the common type of NFI.[4] Studies have shown that NFI is associated with congenital anomalies,pelvic floor neuropathy,central diseases, and systemic diseases, but its anorectal motility characteristics have not still been well elucidated.[4.5] High resolution manometry (HRM) can show the motility changes of anus, rectum and abdominal accurately, which is an effective method for ArNFI diagnosis and evaluation.[6] 
Therefore, the aim of our study was to explore the anorectal dynamic characteristics, psychological characteristics, and quality of life of ArNFI patients.

\section{Methods}

\subsection{Objects}

Inclusion criteriawere as follows[7]: central nervous system damage caused by a definite accident; noncontrolled stool leakage occurred after the accident, but not before; the frequency of stool leakage meets at least two times within 4 weeks; anorectal manometry showed obvious abnormality.

Exclusion criteria were as follows: severe heart and lung diseases, diabetes, nephropathy and other chronic diseases associated with neuropathy or acute intestinal infection or obstruction etc. 26 patients with ArNFI were conducted HRM in gastrointestinal motility center of affiliated provincial hospital of Anhui medical university were collected as research objects from January 2016 to August 2019,Meanwhile, 10 healthy subjects were selected and analysed as control group.

\subsection{Measurements}

\subsubsection{Anorectal High Resolution Manometry (HRM)}

All enrolled patients and healthy subjects underwent the HRM test(GAP-24A type, MedKinetic, Ningbo, China). Patients were instructed to prohibit drugs affecting gastrointestinal motility for 1 week and fasting for 4 to 6 hours before examination. Patients were conformed to defaecate all urine and faeces as far as possible, and take the left knee bending position. The catheter was placed horizontally at the level of the patient's anus and cleared. The catheter was inserted into the position of $7.5 \mathrm{~cm}$. The proximal end was placed in the anal sphincter and the distal end was placed in the rectum. The following tests were conducted: 1) Relaxation test: patients were instructed to relax and breathe calmly for 10 seconds; 2) Contraction test: patients were instructed to contract the anus continuously for 30s; 3) Defecation test: patients were instructed to perform defecation movements continuously for 30s; 4) Sensory test: inflate the balloon slowly to ask patients about their feelings, including initial sensation threshold, initial desire of defecation threshold, strong desire of defecation threshold and maximum tolerated dose. Medview360 pressure analysis software was used to analyze the characteristics of patients' anorectal motility.[8]

\subsubsection{Assessment of mental state}

HAMA (Hamilton anxiety scale) and HAMD (Hamilton depression scale)[9]were both used to reflect the mental state of these patients, and were independently scored by two trained evaluators by conversation and examination. HAMA contains a total of 14 items and HAMD contains a total of 24 items, all of which adopt the 5-grade scoring method of $0 \sim 4$ points, and the standards of all levels are: 0(asymptomatic), 1 (mild), 2(moderate), 3(severe) and 4(extremely severe).

\subsubsection{Survey of quality of life}


SF-36 scale[10] was used to investigate the quality of life of patients, which includes 8 dimensions: physical health function (PF), physical role function (RP), physical pain (BP), general health status (GH), vitality (VT), social function (SF), emotional role (RE) and mental health (MH). Each dimension was converted into final score ( $0 \sim 100$ points) according to the formula. The higher the score, the better the patient's quality of life.

\subsection{Statistical analysis}

EpiData 3.1 software was used to input data and SPSS21.0 software was used for statistical analysis. The normal distribution data is expressed as mean \pm standard deviation; The data with non-normal distribution were represented by the median, range and the $t$-test was used for comparison between the two groups with normal distribution. Wilcoxon rank sum test was used to compare the two groups with non-normal distribution. Counting data and classification variables were analyzed by $c^{2}$ test. The difference was statistically significant with $P<0.05$.

\section{Results}

\subsection{Study Population}

Among the 26 ArNFI patients, the age range is $30 \sim 77$ years old, and the average age is $(47.18 \pm 15.40)$ years old, which include 12 males and 14 females. There were 13 car accidents, 10 accidental falls, and 3 surgical spinal cord injury. There were no significant differences in age, sex and BMI between the ArNFI group and control group. See table 1.

\subsection{Analysis of anorectal motility characteristics}

\subsubsection{Anorectal pressure characteristics}

Anal sphincter resting pressure in the ArNFI group and the control group was $21.18 \pm 4.68 \llbracket 34.83 \pm 14.13$, respectively, and the difference between the two groups was statistically significant $P<0.05$. Anorectal compliance was $11.41 \pm 0.32 \varangle 4.03 \pm 1.06$, respectively, and the difference between the two groups was statistically significant $P<0.05$. Maximal squeeze pressure were $53.66 \pm 14.59 \bigotimes 143.95 \pm 19.82$, respectively, the difference between two groups was statistically significant $(P<0.05)$; There was no statistically significant difference in the rectum resting pressure, anal sphincter length, effective length of anal sphincter, minimum volume of induced RAIR, rectum and anal pressure gradient $(P>0.05)$ between the two groups . See table 2.

\subsubsection{Balloon inflation characteristics}

In the ArNFI group, 10 cases of initial sensory threshold were not extracted, and 16 cases of the value was $85.45 \pm 36.83 \mathrm{ml}$. The initial desire of defecation threshold was not extracted in 18 cases, and the value was $128.25 \pm 59.84 \mathrm{ml}$ in 8 cases. The strong desire of defecation threshold was not extracted in 18 cases, 
and the value of 8 cases was $190.33 \pm 58.79 \mathrm{ml}$. The maximum tolerated dose was not extracted in 18 cases, and the value was $250.50 \pm 28.41 \mathrm{ml}$ in 8 cases. See table 3 .

\subsubsection{Contradictory contraction and cough reflex}

There were 10 and 0 cases of contradictory contraction between the ArNFI group and the control group respectively, and there was no statistically significant difference between the two groups $\left(c^{2}=5.325, P\right.$ $=0.021<0.05$ ). The number of cases with cough reflex in ArNFI group and control group was 18 and 10, respectively, and the difference between the two groups was statistically significant $\left(c^{2}=3.956, P=0.047<\right.$ 0.05). See figure 1.

\subsubsection{Anorectal manometry image}

In the resting state of the ArNFI group, the color band of anorectal pressure is light green, indicating that the anal sphincter resting pressure is low, as shown in figure A. In the state of contraction, the color band of anal pressure in the patient changed from light green to dark green, and the color band of pressure in the abdomen changed from dark blue to light green, indicating that the patient had low anal contraction force and needed to complete anal contraction with the help of abdominal pressure,as shown in figure B. In the state of defecation, the dark blue color bands in the abdomen of the patient changed from dark blue to dark green, while the color bands in the anal changed from light green to dark green, indicating that the patient had contradictory contractions, which may be a compensatory pressure increasion in the anal to avoid the occurrence of incontinence, as shown in figure $\mathrm{C}$.

\subsection{Psychological characteristics}

HAMA scores of the ArNFI group and the control group were $21.29 \pm 2.06$ and $7.63 \pm 1.41$ respectively, the difference between the two groups were statistically significant $(t=14.54, P<0.001)$. HAMD scores were $22.00 \pm 3.70$ and $8.75 \pm 1.91$, respectively, the difference between the two groups were statistically significant $(t=11.63, P<0.001)$. See figure 2 .

\subsection{Life quality characteristics}

SF-36 scale was used to investigate the quality of life of patients and it was found that there were significant differences between ArNFI group and the control group in the 8 dimensions of $\mathrm{PF}, \mathrm{RP}, \mathrm{GH}, \mathrm{VT}, \mathrm{SF}, \mathrm{RE}$ and $\mathrm{MH}$. As shown in table 4.

\section{Discussion}

In this study, we found that ArNFI patients had significantly abnormal anorectal motility characteristics, increased HAMA.HAMD scores, and their life quality was obviously declined. The abnormal anorectal motility is believed to be attributed to the declined life quality and the accompanied anxiety and depressive symptoms. 
Effective defecation control requires the following conditions[11]: 1)the anal sphincter can maintain a certain pressure in the resting state; 2)the anal and rectum have a good sensory function and can cause the corresponding contraction or inhibition of the anal sphincter after receiving relevant stimulation; 3)the rectal wall has good compliance and storage capacity. Anorectal manometry is a important method to evaluate anorectal function.[12] Anorectal manometry in patients with $\mathrm{Fl}$ is characterized by decreased anal resting pressure and maximum squeeze pressure, impaired rectal sensory function and the ability of anal canal dentate line to distinguish intestinal contents, abnormal RAIR or abnormal minimum volume of induced RAIR.[13] Decreased rectal compliance can lead to increased frequency of defecation and a sense of urgency due to decreased rectal fecal storage function so that FI can occur even if the anal sphincter function is normal.[14]

The clinicopathological changes of NFI patients mainly include autonomic control and contractile function of puborectalis and external sphincter decreasely, colon motility and the tension of internal anal sphincter is relatively elevated after the injury of the nervous system.[4.5] The expansion sensory loss of rectal mucosa can not cause desire of defecation or defecation action.Running under the state of excessive expansion consistently can lead to anal sphincter expansion relaxation, shown as "overflowing" : 1) large amount of fecal mass deposition in the rectum and anal canal; 2) anal relaxation; 3) some patients with intestinal fluid discharge and even rectocele and so on.[15] Clinical treatment is mainly aimed at improving nervous system function.

FI seriously affects the quality of life of patients. Studies have shown that Wexner score is correlated with the quality of life of FI patients. When Wexner score $\geq 9$, patients' quality of life is severely damaged, and their community activities are limited and the scope of activities is limited to their home.[16.17.18] Our study alse shown the the life quality of ArNFI patients was significantly lower in PF,RP,BP,GH,VT,SF,RE and $\mathrm{MH}$ than that of the control group which was consistent with the previous studies[16.17.18]. Meanwhile, the HAMA,HAMD scores of ArNFI patients were significantly lower than those of the control group which were similar to the previous study .[19.20]

Currently, no drug is effective for $\mathrm{NFI}$, and the goal of drug therapy is to reduce defecation frequency and improve feces propertie.[21.22] A meta-analysis included 16 randomized controlled study shown that application of loperamide or phenylethyl piperidine plus atropine can reduce the sense of defecation urgency and Fl, help faeces forming, reduce the use of sanitary pad compared with placebo, but there were no significant differences of the anorectal physical examination before and after treatment. Compared with phenylethyl piperidine, loperamide is more effective, less adverse reaction of the central nervous system.[23] Biofeedback therapy is recommended if anal-rectal manometry shows that the weakness of the external anal sphincter in patients with FI or decreased rectal sensory function due to nerve injury.[24.25] Biofeedback is a painless and noninvasive cognitive training of pelvic floor and abdominal wall muscles, especially in patients with complete anal sphincter and reduced rectal sensory function. However, biofeedback treatment is ineffective for FI patients caused by isolated internal sphincter weakness, behavioral or psychiatric disorders, part of neurogenic, rectal resection, inflammation or stenosis, and obvious anal sphincter structural damage.[26] The success rate of biofeedback treatment 
is 38\% 100\%.[27] Neuromodulation is also an effective treatment. Many reports have shown that sacral nerve stimulation can improve the symptoms of Fl. Compared with percutaneous tibial nerve stimulation, sacral nerve stimulation can significantly improve functional outcomes and quality of life in NFI patients and no serious adverse events were found so far.[28.29.30]

In recent years, only a few studies of NFI have been published on Pubmed, and most of these studies are related to congenital deformity in children.[31.32] In addition, few report of NFI caused by accidents. There are some shortcomings in these study: $\otimes$. Currently, diagnostic criteria of ArNFI are still lacking, and relevant literatures have not provided strict diagnostic criteria for ArNFI. \. With a small sample size, the large-scale and multi-center research is expected to be applied in this project. We think the diagnosis of ArNFI should be related to the following points: 1) There are definite accidents that cause central nervous system damage, such as crash, falls, surgery, etc. 2) There is a specific time node and FI occurred after the accident, but not before; 3 ) Have a long course of illness and meet the diagnosis of $\mathrm{Fl}$.

\section{Conclusions}

In summary ,this study shown significantly abnormal anorectal motility characteristics, increased anxiety and depressive symptoms, and obviously declined life quality in patients with ArNFI. Further research is necessary to better understand the anorectal motility characteristics,the clinical characteristics and the natural history of ArNFI patients. Exploration of the diferent therapeutic modalities for ArNFI is crucial to standardise its management.[33]

\section{Abbreviations}

FI Fecal incontinence

NFI Neurogenic fecal incontinence

ArNFI Accident-related neurogenic fecal incontinence

BMI Body Mass Index

HRM High resolution manometry

HAMA Hamilton anxiety scale

HAMD Hamilton depression scale

SF-36 The Medical Outcomes Study item short from health survey

PF Physical health function

RP Physical role function 
BP Physical pain

$\mathrm{GH}$ General health status

VT Vitality

SF Social function

RE Emotional role

$\mathrm{MH}$ Mental health

RAIR Rectal anal inhibitory reflex

\section{Declarations}

Acknowledgements: Not applicable.

Funding: The study was supported by External Science and Technology Cooperation Planning Projects of Anhui Province of China $₫$ No.1604b0602021区,Traditional Chinese medicine scientific research planing Project of Anhui Provincial Commission of Health and Family Planning冈No.2016zy07).

Availability of data and materials: All data generated or analyzed during this study are included in this published article.

Author contributions: Yue Yu,Jie Liu contributed to plan the study; Ruiling Wei, Dewei Wu, Hulin Chen ,Juan Dong, Chaolan Lv, Xiuli Zhu contributed to conduct the study; Jie Liu and Ruiling Wei contributed to collect and interpret data; and Jie Liu,Yue Yu contributed to draft the manuscript.

Competing interests: The authors declare that they have no competing interests.

Consent for publication: Not applicable.

Ethics approval and consent to participate: The protocol was approved by Ethics Committee of Anhui Provincial Hospital Dated June 15th 2015, and all patients joined the study with written informed consent for research use of their survey datas. The guidelines of Helsinki Declaration were followed.

Contributor Information: Yue Yu; E-mail: yuyuemd@163.com

\section{References}

1.van Meegdenburg MM, Meinds RJ, Trzpis M, Broens PMA.Subtypes and symptoms of fecal incontinence in the Dutch population: a cross-sectional study.Int J Colorectal Dis 2018; 33(7): 919-925. 
2.Guillaume A, Salem AE, Garcia P, Chander Roland B.Pathophysiology and Therapeutic Options for Fecal Incontinence.J Clin Gastroenterol 2017 ;51(4):324-330

3.Psychological and Physical Environmental Factors in the Development of Incontinence in Adults and Children: A Comprehensive Review. J Wound Ostomy Continence Nurs 2017; 44(2)区E1.

4.Elmelund M, Klarskov N, Biering-Sørensen F.Fecal Incontinence and Neurogenic Bowel Dysfunction in Women With Traumatic and Nontraumatic Spinal Cord Injury.

Dis Colon Rectum 2019 ;62(9):1095-1104.

5.Ledgerwood-Lee M, Zifan A, Kunkel DC, Sah R, Mittal RK.High-frequency ultrasound imaging of the anal sphincter muscles in normal subjects and patients with fecal incontinence. Neurogastroenterol Motil $2019 ; 31(4): \mathrm{e} 13537$.

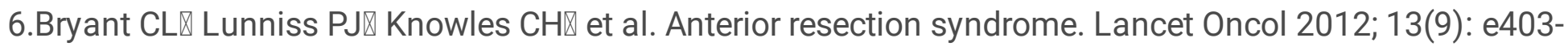
e408.

7.Simren M, Palsson OS, Whitehead WE. Update on Rome IV Criteria for Colorectal Disorders: Implications for Clinical Practice. Current Gastroenterology Reports 2017;19(4):15.

8.Liu Z, Ge Y, Xu F, Xu Y, Liu Y, Xia F, Lin L, Chen JDZ. Preventive effects of transcutaneous electrical acustimulation on ischemic stroke-induced constipation mediated via the autonomic pathway.Am J Physiol Gastrointest Liver Physiol 2018 ;315(2):G293-G301.

9.Zimmerman M, Martin J,Clark H,McGonigal P,Harris L,Holst CG. Measuring anxiety in depressed patients: A comparison of the Hamilton anxiety rating scale and the DSM-5 Anxious Distress Specifier Interview. J Psychiatr Res 2017; 93:59-63.

10.Treanor C, Donnelly M.A methodological review of the Short Form Health Survey 36 (SF-36) and its derivatives among breast cancer survivors.Qual Life Res. 2015 Feb;24(2):339-62

11.Wald A.Diagnosis and Management of Fecal Incontinence. Curr Gastroenterol Rep 2018;

20(3):9.

12. Heitmann PT, Rabbitt P, Schloithe A, Patton V, Skuza PP, Wattchow DA, Dinning PG.

Relationships between the results of anorectal investigations and symptom severity in patients with faecal incontinence.Int J Colorectal Dis 2019;34(8):1445-1454.

13.Fernández-Fraga X,Azpiroz F,Malagelada JR. Significance of pelvic floor muscles in anal incontinence. Gastroenterology 2002;123(5) : 1441-1450区

14.Meinds RJ, Timmerman MEW, van Meegdenburg MM, Trzpis M, Broens PMA. 
Reproducibility, feasibility and validity of the Groningen Defecation and Fecal Continence questionnaires.Scand J Gastroenterol 2018;53(7):790-796.

15.Ingersoll Z,Garza-Chapa JI,Pham R,Malouf P,Susa J,Weis S. Recurrent Granuloma Gluteale Infantum Secondary to Fecal Overflow Incontinence.Case Rep Dermatol 2018, 10(2): 203-207.

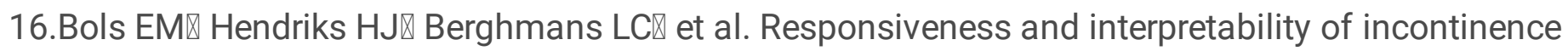
severity scores and FIQL in patients with fecal incontinence『a secondary analysis from a randomized controlled trial . Int Urogynecol J 2013, 24(3):469-478.

17.Lynne B, Nowak M,Yik-Hong H. Impact of fecal incontinence on quality of life. World J Gastroenterol 2009, 15(26):3276-3282.

18.Peterson AC, Sutherland JM, Liu G, Crump RT, Karimuddin AA.Evaluation of the Fecal Incontinence Quality of Life Scale (FIQL) using item response theory reveals limitations and suggests revisions.Qual Life Res 2018;27(6):1613-1623.

19.Hunt MG,Wong C,Aajmain S,Dawodu I. Fecal incontinence in people with self-reported irritable bowel syndrome: Prevalence and quality of life. J Psychosom Res 2018; 113:45-51.

20.Bailey N, Parés D. Faecal incontinence and depression: cause or effect? Colorectal Dis 2010; 12(5):397398.

21.Saldana Ruiz N, Kaiser AM.Fecal incontinence - Challenges and solutions. World J Gastroenterol 2017; 23(1):11-24.

22.Jelovsek JE, Markland AD, Whitehead WE, Barber MD, Newman DK, Rogers RG, Dyer K, Visco AG, Sutkin G, Zyczynski HM, Carper B, Meikle SF, Sung VW, Gantz MG; National Institute of Child Health and Human Development Pelvic Floor Disorders Network. Controlling faecal incontinence in women by performing anal exercises with biofeedback or loperamide: a randomised clinical trial. Lancet Gastroenterol Hepatol 2019;4(9):698-710.

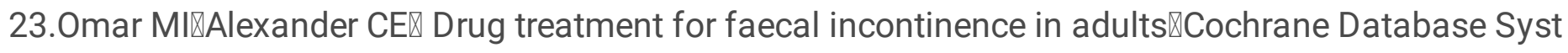
Rev,2013,CD002116.

24.Kim KH,Yu CS,Yoon YS, et al. Effectiveness of biofeedback therapy in the treatment of anterior resection syndrome after rectal cancer surgery. Dis Colon Rectum,2011,54(9)凶1107-1113.

25.Bardsley A.Assessment, prevention and treatment of faecal incontinence in older people.

Nurs Older People 2018;30(6):39-47.

26.Bartlett L, Sloots K, Nowak M, et al. Biofeedback therapy for symptoms of bowel dysfunction following surgery for colorectal cancer . Tech Coloproctol 2011; 15(3):319-326. 
27.Parker $\mathrm{CH}$,Henry S,Liu LWC.Efficacy of Biofeedback Therapy in Clinical Practice for the Management of Chronic Constipation and Fecal Incontinence.J Can Assoc Gastroenterol 2019; 2(3):126-131.

28.Sreepati G, James-Stevenson T.Use of Sacral Nerve Stimulation for the Treatment of Overlapping Constipation and Fecal Incontinence.Am J Case Rep 2017;18:230-233.

29.Simillis C, Lal N, Qiu S, Kontovounisios C, Rasheed S, Tan E, Tekkis PP.Sacral nerve stimulation versus percutaneous tibial nerve stimulation for faecal incontinence: a systematic review and meta-analysis. Int $\mathrm{J}$ Colorectal Dis 2018;33(5):645-648.

30.Cohen-Zubary N, Gingold-Belfer R, Lambort I, Wasserberg N, Krissi H, Levy S, Niv Y, Dickman R.Home electrical stimulation for women with fecal incontinence: a preliminary randomized controlled trial.Int $\mathrm{J}$ Colorectal Dis 2015;30(4):521-528.

31.Cushing CC,Martinez-Leo B,Bischoff A,Hall J,Helmrath M,Dickie BH,Levitt MA,Peña A,Zeller MH,Frischer JS. Health-Related Quality of Life and Parental Stress in Children With Fecal Incontinence: A Normative Comparison. J Pediatr Gastroenterol Nutr 2016;63(6):633-636.

32.Donkol RH, Al-Nammi A.Percutaneous cecostomy in the management of organic fecal incontinence in children.World J Radiol 2010;2(12):463-467.

33.Lin H, Zhang Z, Hu G, Wang X, Lin C, Chen Y.Acupuncture for fecal incontinence: Protocol for a systematic review and data mining.Medicine (Baltimore) $2019 ; 98(7): e 14482$.

\section{Tables}

Гable1. Demographics for the 2 study groups

\begin{tabular}{|c|c|c|c|}
\hline Variables & $\begin{array}{l}\text { Healthy controls } \\
\qquad(\mathrm{n}=10)\end{array}$ & $\operatorname{ArNFI}(\mathrm{n}=26)$ & $P$-value \\
\hline Age (media,range)/years & $31(27-64)$ & $35(30-77)$ & 0.466 \\
\hline Sex(male,\%) & $5(50.0 \%)$ & $12(46.2 \%)$ & 0.497 \\
\hline $\begin{array}{l}\text { Body mass index } \\
\text { (media,range) }\end{array}$ & $24(17-34)$ & $22(18-35)$ & 0.097 \\
\hline $\begin{array}{l}\text { Course of disease } \\
\text { (media,range)/years }\end{array}$ & I & $6(3-9)$ & I \\
\hline
\end{tabular}

ArNFI:Accident-related neurogenic fecal incontinence 
[able 2. The comparisons of anorectal pressure characteristics for the 2 study groups

\begin{tabular}{|c|c|c|c|c|}
\hline Variables & $\begin{array}{l}\text { Healthy controls } \\
\qquad(\mathrm{n}=10)\end{array}$ & $\operatorname{ArNFI}(\mathrm{n}=26)$ & $t$-value & $P$-value \\
\hline anal sphincter resting pressure $(\mathrm{mmHg})$ & $34.83 \pm 14.13$ & $21.18 \pm 4.68$ & 2.943 & 0.011 \\
\hline rectal resting pressure $(\mathrm{mmHg})$ & $19.81 \pm 8.49$ & $20.73 \pm 4.31$ & 0.170 & 0.868 \\
\hline anal sphincter length(cm) & $3.16 \pm 0.61$ & $3.33 \pm 0.89$ & 0.418 & 0.683 \\
\hline the effective length of anal sphincter $(\mathrm{cm})$ & $2.23 \pm 0.64$ & $1.56 \pm 0.67$ & 1.950 & 0.073 \\
\hline rectal compliance(cc/mmHg) & $4.03 \pm 1.06$ & $1.41 \pm 0.32$ & 3.929 & 0.002 \\
\hline minimum volume of induced RAIR(ml) & $21.25 \pm 6.21$ & $14.29 \pm 5.34$ & 0.877 & 0.396 \\
\hline rectal-anal pressure gradient(mmHg) & $-21.70 \pm 6.38$ & $-19.65 \pm 4.98$ & 0.150 & 0.883 \\
\hline maximal squeeze pressure(mmHg) & $143.95 \pm 19.82$ & $53.66 \pm 14.59$ & 3.234 & 0.007 \\
\hline
\end{tabular}

ArNFI:Accident-related neurogenic fecal incontinence; RAIR: rectal anal inhibitory reflex

[able 3.The comparisons of balloon inflation characteristics for the 2 study groups 


\begin{tabular}{cccc}
\hline \multirow{2}{*}{ Variables } & $\begin{array}{c}\text { Healthy controls } \\
(\mathrm{n}=10)\end{array}$ & \multicolumn{2}{c}{ ArNFI(n=26) } \\
& $\pm \mathrm{s}(\mathrm{ml})$ & $\begin{array}{c}\text { extracted } \\
\pm \mathrm{s}(\mathrm{ml})\end{array}$ & $\begin{array}{c}\text { not extracted } \\
\square \mathrm{n}, \% \square\end{array}$ \\
\hline initial sensation threshold & $36.63 \pm 17.93$ & $85.45 \pm 36.83$ & $10,38.5 \%$ \\
initial desire of defecation threshold & $87.50 \pm 42.64$ & $128.25 \pm 59.84$ & $18,69.2 \%$ \\
& & & $18,69.2 \%$ \\
strong desire of defecation threshold & $158.75 \pm 74.23$ & $190.33 \pm 58.79$ & \\
& & & $18,69.2 \%$ \\
\hline
\end{tabular}

ArNFI:Accident-related neurogenic fecal incontinence

[able 4.The comparisons of life quality scores(SF-36) for the 2 study groups

\begin{tabular}{|c|c|c|c|c|c|c|c|c|}
\hline Variables & $\begin{array}{c}\text { Physicl } \\
\text { functioning }\end{array}$ & $\begin{array}{c}\text { Role- } \\
\text { physical }\end{array}$ & $\begin{array}{l}\text { Bodily } \\
\text { Pain }\end{array}$ & $\begin{array}{l}\text { General } \\
\text { healthy }\end{array}$ & Vitality & $\begin{array}{c}\text { Socail } \\
\text { functioning }\end{array}$ & $\begin{array}{c}\text { Role } \\
\text { emotional }\end{array}$ & $\begin{array}{l}\text { Mental } \\
\text { Healthy }\end{array}$ \\
\hline $\begin{array}{l}\text { Healthy } \\
\text { controls } \\
(\mathrm{n}=10)\end{array}$ & $1.78 \pm 0.99$ & $1.64 \pm 1.18$ & $1.75 \pm 0.89$ & $2.15 \pm 1.17$ & $1.67 \pm 1.03$ & $1.54 \pm 0.94$ & $2.27 \pm 0.94$ & $1.83 \pm 0.706$ \\
\hline $\begin{array}{l}\text { ArNFI } \\
\square \mathrm{n}=26 \square\end{array}$ & $0.71 \pm 0.86$ & $0.62 \pm 0.79$ & $0.92 \pm 0.85$ & $0.77 \pm 0.89$ & $0.66 \pm 0.82$ & $0.64 \pm 0.81$ & $1.58 \pm 0.82$ & $0.84 \pm 0.600$ \\
\hline$t$-value & 14.535 & 14.407 & 11.631 & 17.699 & 14.272 & 12.984 & 9.636 & 18.729 \\
\hline$P$-value & $<0.01$ & $<0.01$ & $<0.01$ & $<0.01$ & $<0.01$ & $<0.01$ & $<0.01$ & $<0.01$ \\
\hline
\end{tabular}

ArNFI:Accident-related neurogenic fecal incontinence

Figures 


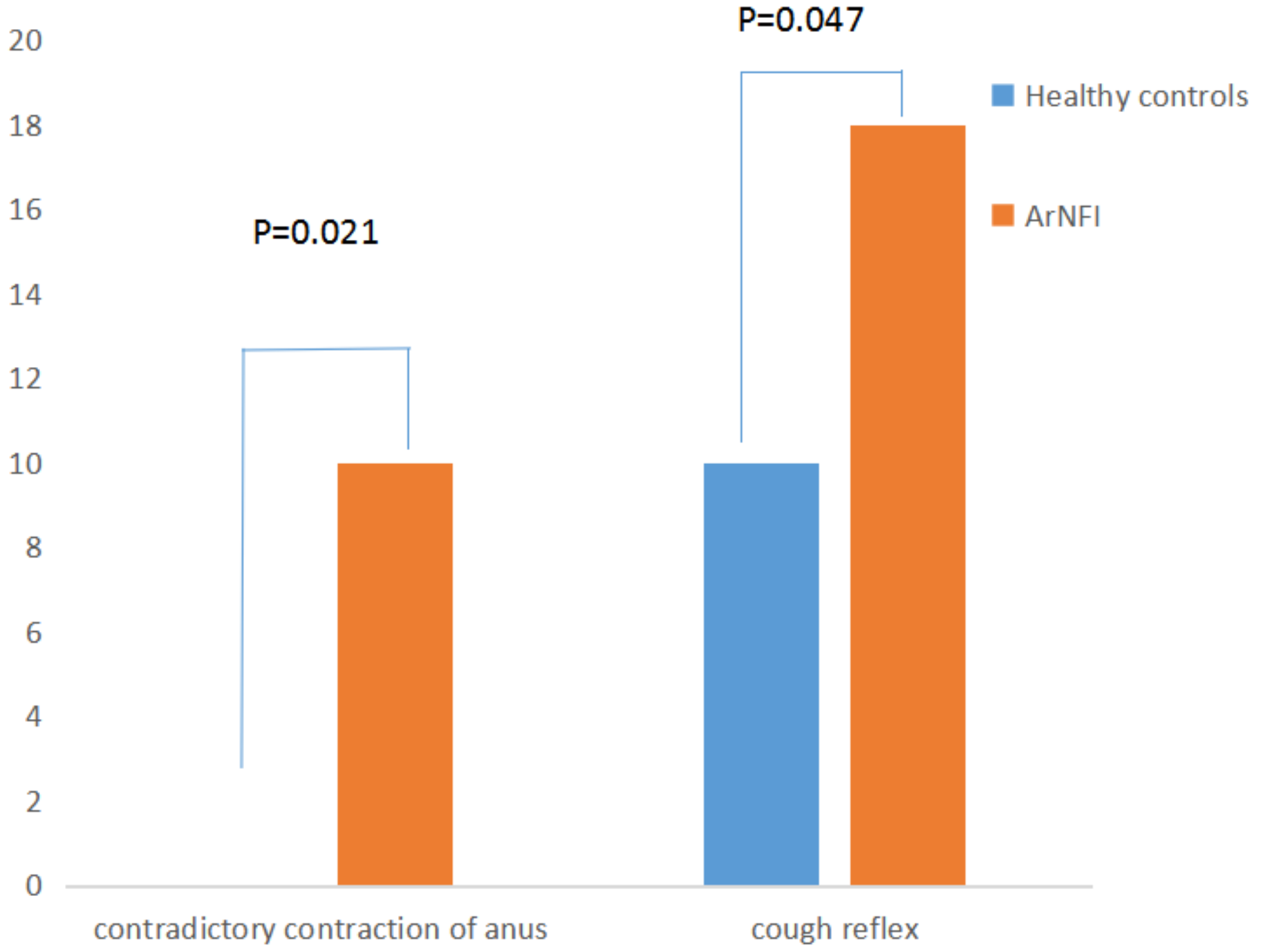

Figure 1

Figure 1 


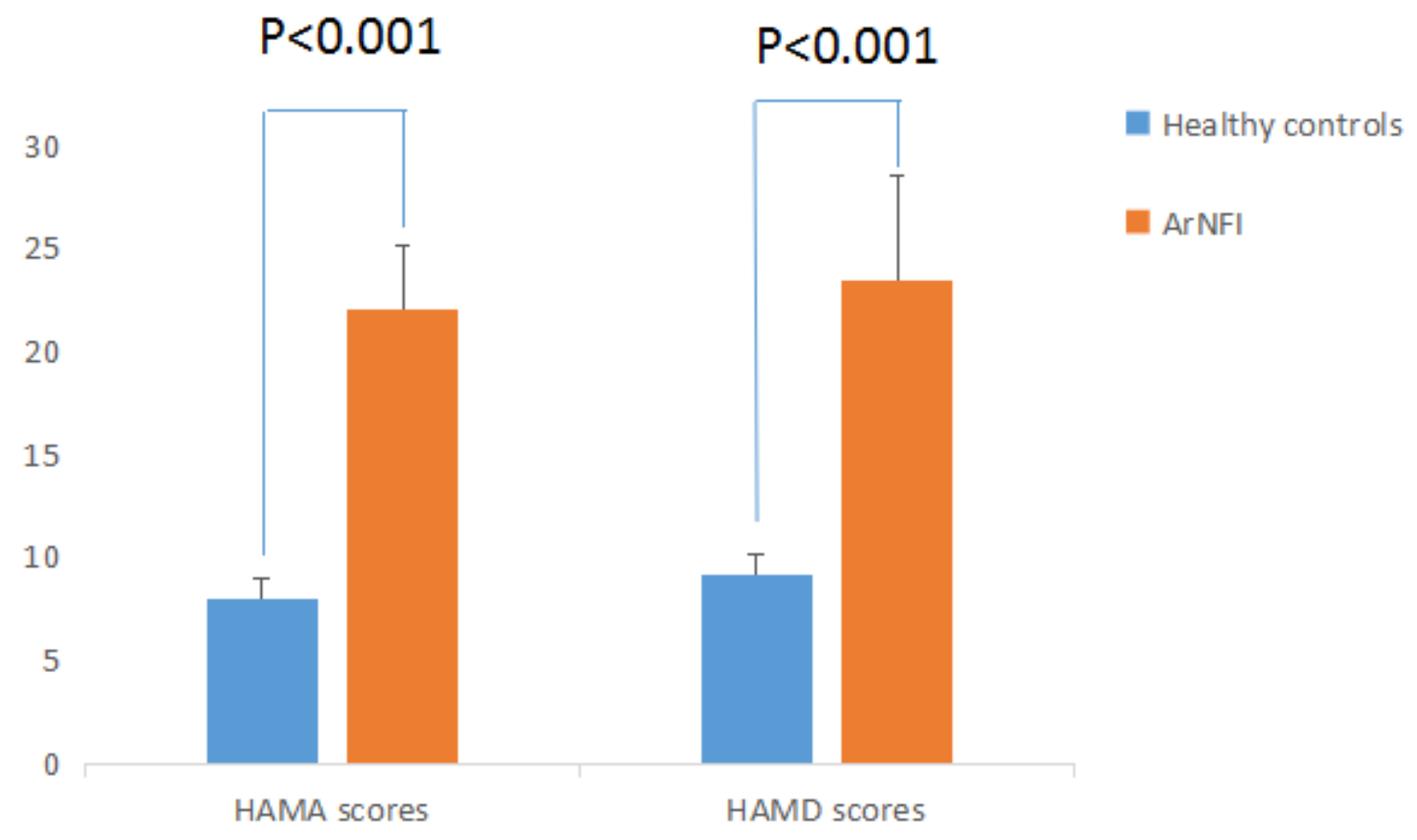

Figure 2

Figure 2

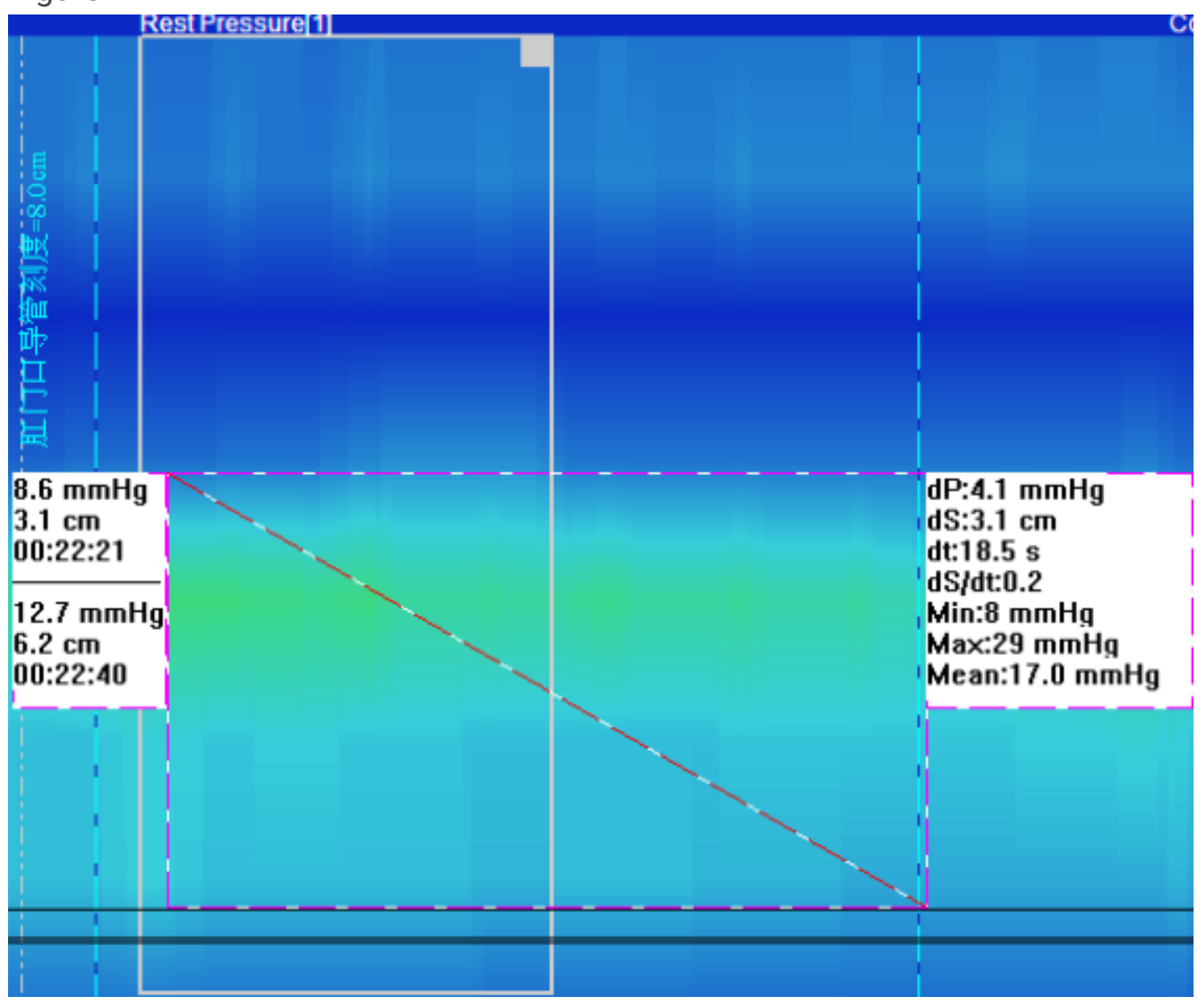

Figure 3 
Figure A

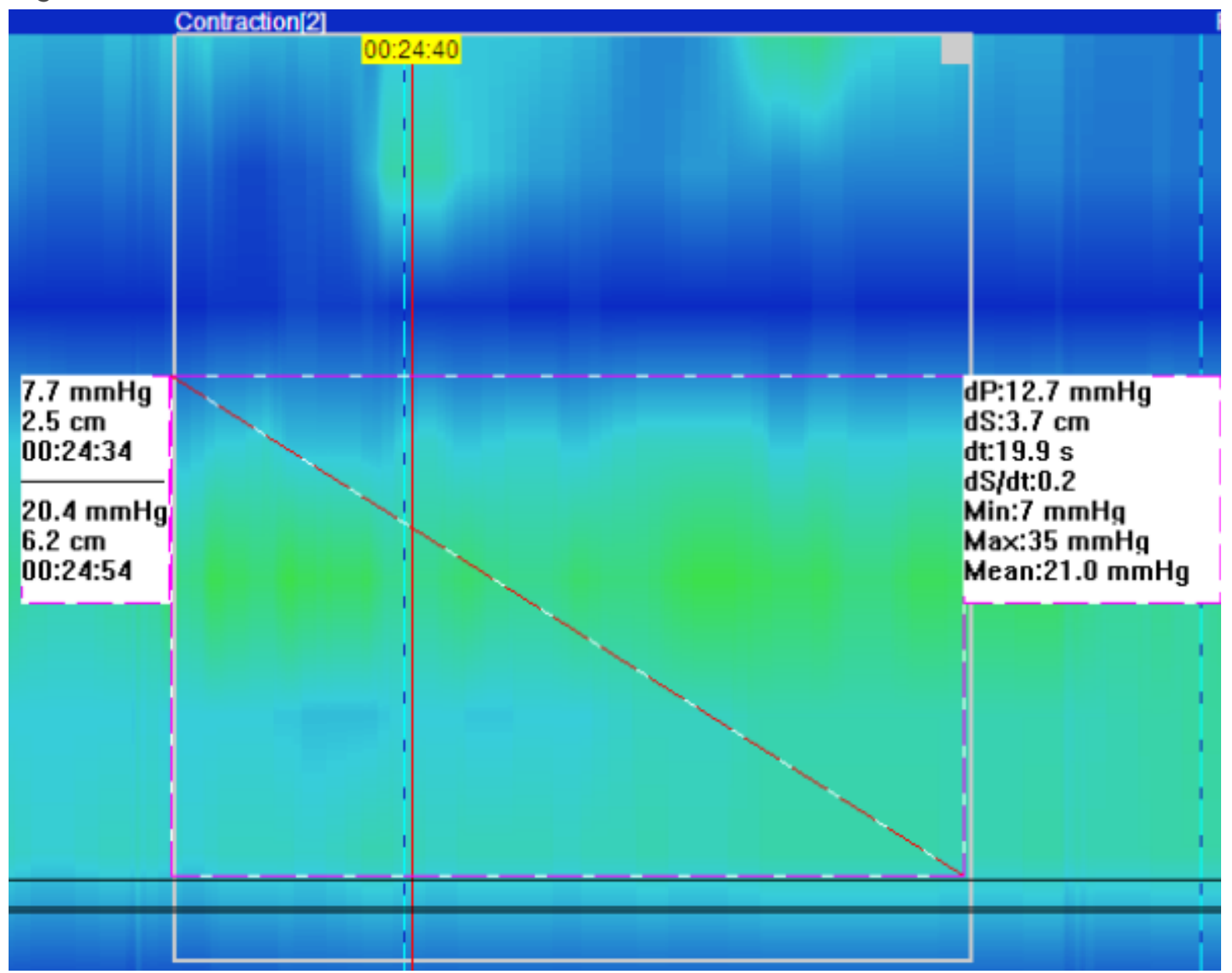

Figure 4

Figure B 


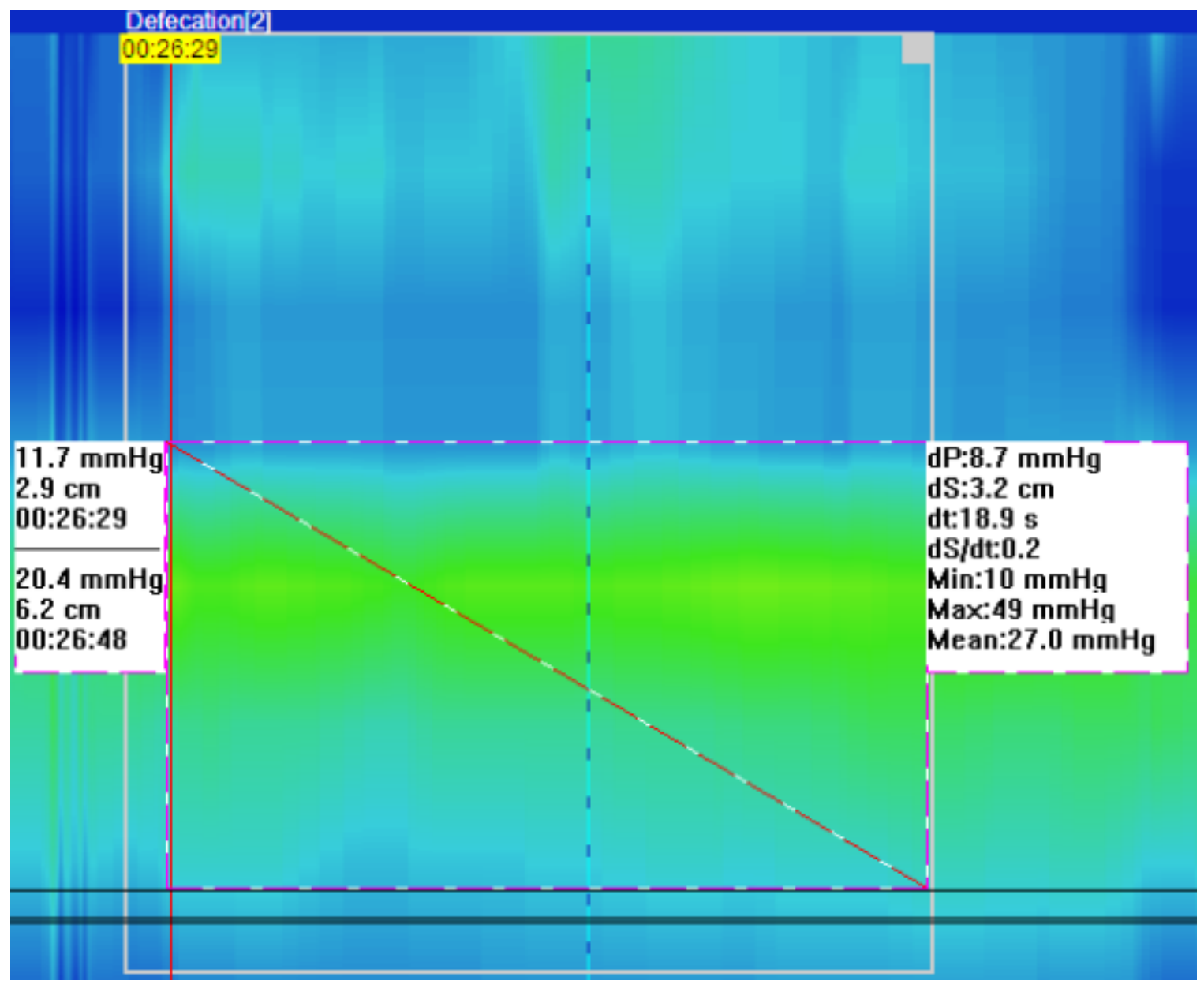

Figure 5

Figure $\mathrm{C}$

\section{Supplementary Files}

This is a list of supplementary files associated with this preprint. Click to download.

- oringinaldata.xls 